\section{Aureliano Puglionisi}

\section{Giorgio Guarnera \\ Vascular Surgeon, Rome, Italy}

\section{The 70's}

The 1970's have been a particularly intense and difficult historical-cultural period for Italy. In addition to successes in the sports field (defeat in the final with Brazil at the Football World Cup in 1970) and achievements in the social field (confirmation of the law on divorce in 1974), it was a period of great unrest for the young, with the occupations (sit-ins) of the universities. But above all, those have been the years of terrorism, attacks, the Red Brigades: the socalled Years of Lead.

At the beginning of that era, in 1971, after passing the admission tests (then required only in that university) I enrolled at the Faculty of Medicine and Surgery of the Catholic University of the Sacred Heart of Rome. After the first three years spent in biological institutes, I was admitted at the Gemelli hospital and, in 1974, I applied for an internship at the Institute of Special Surgical Pathology and Clinical Propedeutics directed by Prof. Aureliano Puglionisi.

That institute was renowned for the high-quality level of surgery that was practiced in the vascular, biliary, endocrine, thorax, abdomen, and pediatric fields. I was immediately attracted by vascular surgery, the field that was so dear to Prof. Puglionisi, who had cultivated it for years under the guidance of his master, Prof. Edmondo Malan, universally recognized as the father of Italian vascular surgery. Prof Puglionisi had published innovative works on vascular malformations of the lower limbs with Prof. Malan. ${ }^{1,2}$

\section{Venous thrombectomy}

In 1972, Prof. Puglionisi and his collaborators, in the context of the $64^{\text {th }}$ Congress of the Italian Society of Surgery, had curated an extensive and exhaustive dissertation on the Problems of the surgical treatment of acute venous thrombosis of the lower limbs, which was published in the Society's proceedings. ${ }^{3}$ With methodological rigor and clinical acumen, after taking into account the strengths and weaknesses of anticoagulant and thrombolytic therapies, the text outlined the indications and objectives of venous thrombectomy (Tables 1 and 2).

The issues and methods of surgical pro- cedures were extensively discussed (to be later resumed in a subsequent publication on the prestigious Treaty of Surgical Technique published by UTET), ${ }^{4}$ with a special focus on the sequence of the positioning of balloon catheters: the first was to be introduced into the inferior vena cava, through the long saphenous vein of the healthy side for protection from pulmonary embolism, and the second iliac protective catheter was to be introduced through the phlebotomy, into the femoral vein of the side affected by the thrombosis; then the caval catheter had to be deflated and the iliac catheter inflated to maintain protection and restore flow in the vena cava; finally, the catheter indicated to remove the obstruction had to be introduced in contact with the protection balloon (Figure 1).

The publication also explained the risk and difficulties of advancement of the catheters due to the presence of an adhesive thrombosis at the level of the common iliac vein or of the engagement of the catheter in the lumbar vein, which, especially on the left, is in line with the main venous axis (Figure 2). In particular, the importance of knowing the seat and extent of the thrombus and the time of onset was emphasized; it was also stated that there may be a discrepancy between the real beginning of the thrombotic process and its clinical manifestation, so that it is not uncommon to note, at the intervention, mixed forms in which, alongside an ancient thrombosis, organized, adherent to the venous wall, not totally occluded, recent thrombi are present, which have caused complete blockage of the venous lumen and the onset of clinical symptomatology (Figure 3). These statements appear to be absolutely acceptable

Table 1. Venous thrombectomy: objectives (Puglionisi, 1972).

Immediate

Prevention of extension of thrombus and of pulmonary embolism

Quick reduction of local symptoms

Late

Preservation of venous patency

Prevention of postthrombotic syndrome

Table 2. Venous thrombectomy: indications (Puglionisi, 1972).

\section{Immediate}

Iliofemoral venous thrombosis with floating thrombus and embolic risk

Iliofemoral venous thrombosis refractory to anticoagulants or embologenic

Phlegmasia coerulea dolens

Recent and extensive thrombophlebitis of the upper limb

Thrombosis of the saphenofemoral junction witn thrombus protruding into the femoral vein (niorgio Guarnera, Vascular Surgeon, Studio Appia 197, via Appia 197, Rome, Italy.

Key words: Italian Phlebolymphology; history; Masters of the past; phlebology; lymphology.

Conflict of interests: the author declares no

This paper is part of the monographic issue: 'Did the Masters of the past know the future? History update of Italian Phlebolymphology' - Guest edited by G. Agus; Phlebolooy - Part II edited by

Received for publication: 30 June 2020.

Revision received: 10 July 2020

This work is licensed under a Creative Commons Attribution 4.0 License (by-nc 4.0).

${ }^{\circ}$ Copyright: the Author(s), 2020

Licensee PAGEPress, Italy

and Lymphatics 2020:9.9252

doi:10.4081/vl.2020.9252

today, now that we can have non-invasive diagnostic methods such as cho-color Doppler, while then the refermethod was only phlebography.

Although within the diagnostic limits of and also therapeutic limits (for possible treatment of residual stenoPuglionisi stated that venous thrombecomy could be considered the most effective means of preventing pulmonary embolism 
and the outcome at a distance of venous obstruction. This statement is confirmed and supported in recent publications. ${ }^{5,6}$

\section{Experimental surgery}

I spent three years in the Institute, following mainly patients with vascular and venous disease in particular. Since the Institute also had a stabulary for experimental surgery, I asked there for my thesis, which was assigned to me in experimental venous surgery, with the guidance and support of a brilliant Collaborator of Prof. Puglionisi, who would have had a very important part in my professional life, Sante Camilli.

The title of the thesis, which was then published, ${ }^{7}$ was Replacement of the inferior vena cava with double velour Dacron prosthesis. Experimental study. The rationale of the study was that the lesions of the inferior vena cava, especially in the supra-renal tract, pose serious problems from the point of view of the surgical technique, also due to the lack of an autologous replacement material of ready availability. Dogs were used as experimental animals, to which a double-velour Dacron prosthesis was implanted in the supra-renal portion of the inferior vena cava. After 3 months of grafting, control cavography was performed and the animals were sacrificed and subjected to autopsy. It was observed that the prosthesis was rapidly and perfectly incorporated and its luminal surface was uniformly coated with a shiny, smooth and well adherent neointimal layer to the underlying fibrous plane. However, because of its insufficient rigidity, the prosthesis could not oppose the external pressure and was gradually blocked in a stenotic attitude (Figure 4).

\section{Implications of cava veins in General Surgery}

The clinical and technical problems related to the surgery of the inferior vena cava were taken up by the group of Prof. Puglionisi in the context of a Symposium on the vascular implications in General Surgery during the $82^{\text {nd }}$ National Congress of the Italian Society of Surgery in 1980. On that occasion, with the hope of an even greater collaboration between the General and Vascular Surgeon, the difficulties of a prosthetic reconstruction of the inferior vena cava, especially in the subdiaphragmatic territory, were re-discussed relatively to the low pressure in the venous system. With extensive illustrations and technical details, cases of inferior and superior vena cava implications were then presented in general, election and urgency surgery. ${ }^{8}$ In a subsequent publication, a clinical case study was presented on the treatment of inferior vena cava thrombosis with indications for the different types of operation and their technical modalities (thrombectomy, caval clip, Mobin Uddin umbrella). ${ }^{9}$

\section{Neurovascular compression syn- dromes of the upper limb}

The school of Prof. Puglionisi paid particular attention to the neurovascular compression syndromes of the upper limb, stressing and demonstrating how they were sustained by a complex morpho-dynamic

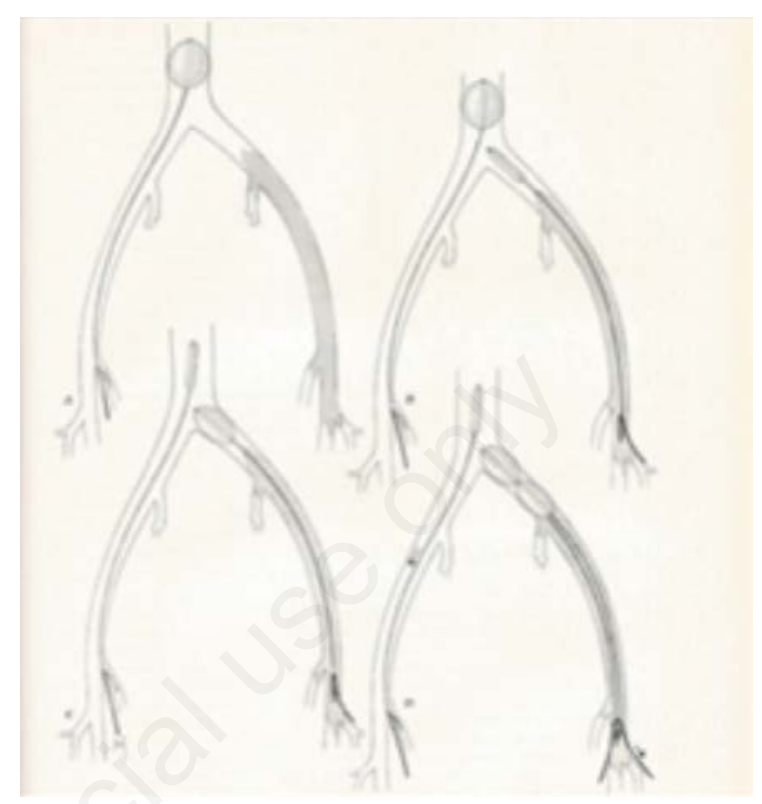

Figure 1. Venous thrombectomy technique.

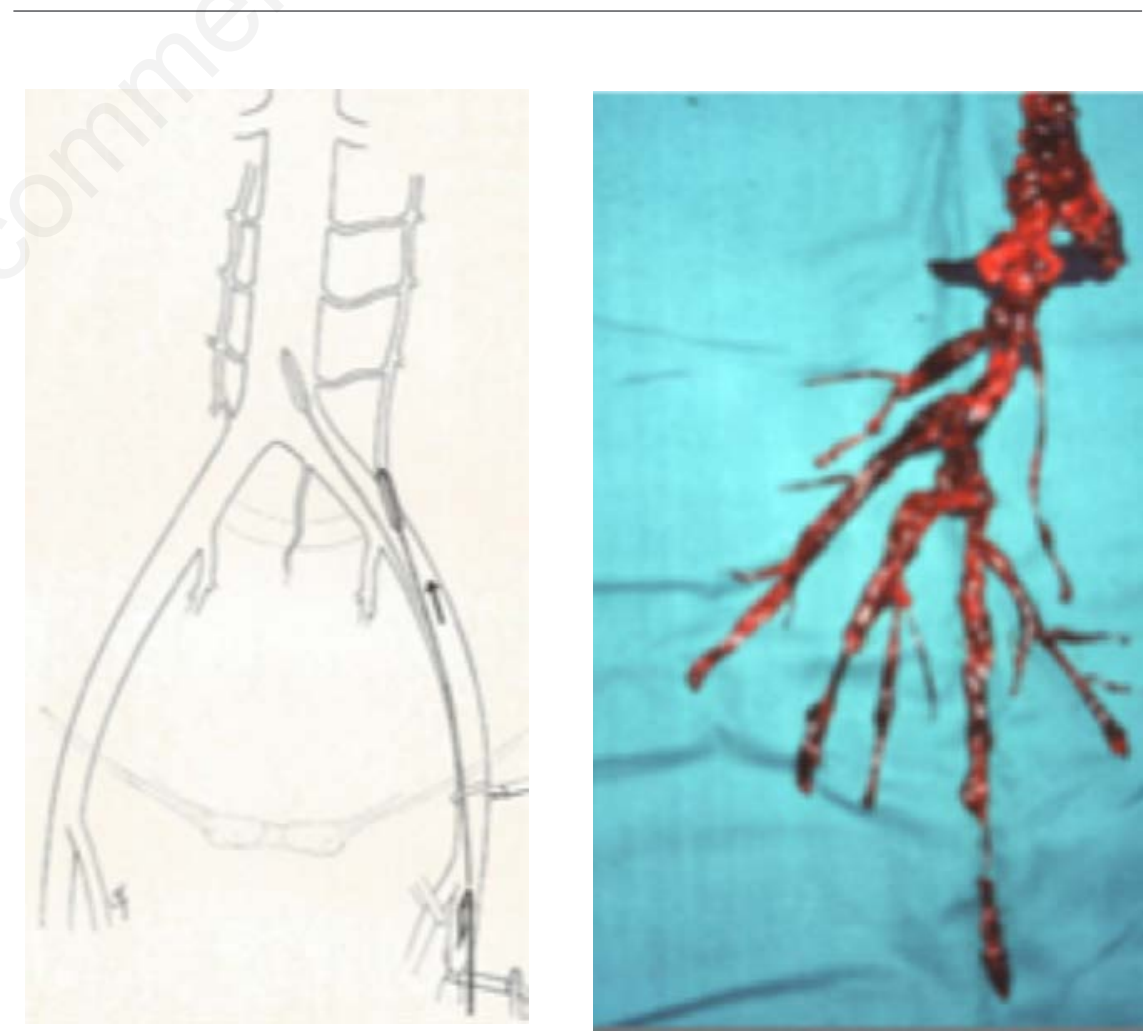

Figure 2. Engaging the catheter in the lumbar vein.

Figure 3. Massive venous thrombosis, with organized and recent thrombi. 


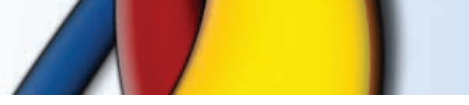

anomaly and that the pathogenetic responsibility was to be attributed, rather than to the individual structures, to a static or dynamic alteration of the relationships between such structures. After recalling the importance of physical semeiotics, the diagnostic importance of dynamic angiography was affirmed and the involvement of the succlavo-axillary venous axis in its own casistic (Figure 5). In the light of the physiopathological, diagnostic and clinical findings, the therapeutic possibilities were discussed and the validity of the anterior scalenotomy intervention was established by the supraclavicular route, especially in cases of obstructed venous outflow. ${ }^{10-12}$

\section{Scientific activity}

The constant development of Vascular surgery and the education to innovations and research has led to an ever-vigilant attention to Italian and foreign publications. In this context Camilli and I translated from English a volume on the diagnosis and treatment of peripheral vascular disease, with the presentation of Prof. Puglionisi. Specific chapters were devoted to deep vein thrombosis, pulmonary embolism, postphlebitic syndrome, and aggressive behavior in deep vein thrombosis and chronic venous insufficiency. ${ }^{13}$

\section{Reconstructive venous surgery}

The particular attention to the pathology of the deep venous circle, the wide clinical case study and the studies of experimental surgery have left an important trace in the cultural baggage of The Students of Prof. Puglionisi. With Camilli I published in 1991 a book on primary deep venous insufficiency and the possibilities of reconstructive surgery. We highlighted the existence of a primary, often misknown, deep venous insufficiency, which could be the cause of chronic venous disease, recurrent varices, and venous ulcers. The various surgical techniques for correcting deep venous reflux and the possibilities of external valvuloplasty with prosthetic sleeve in the early stages of the primitive disease were also examined, when wall dilation had not yet caused excessive prolapse of the valve leaflets (Figure 6). ${ }^{14}$ In subsequent publications the physiopathological, technical and clinical aspects of deep vein disease $\mathrm{e}^{15-17}$ were further examined.
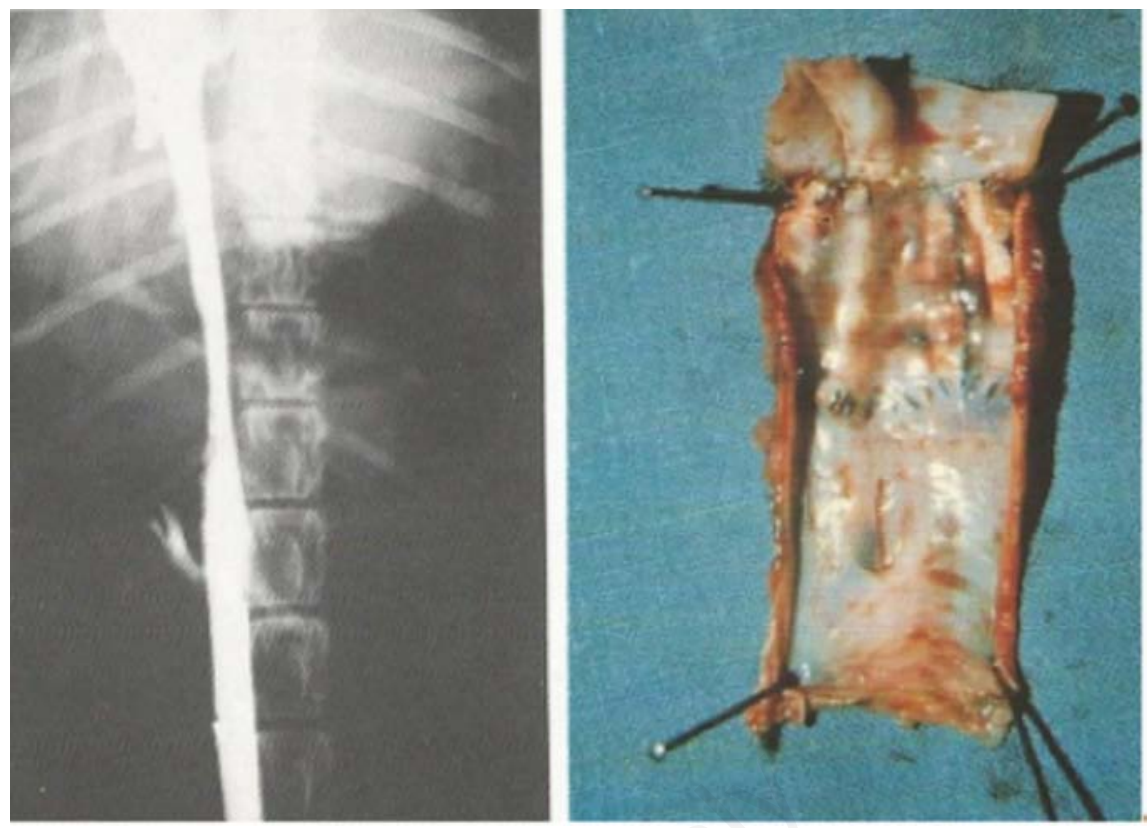

Figure 4. The cavography documents stenosis of the caval graft. At autopsy finding, the graft appears rigid, of fibrous consistency and has an inner surface covered with a thin film, smooth and glossy.

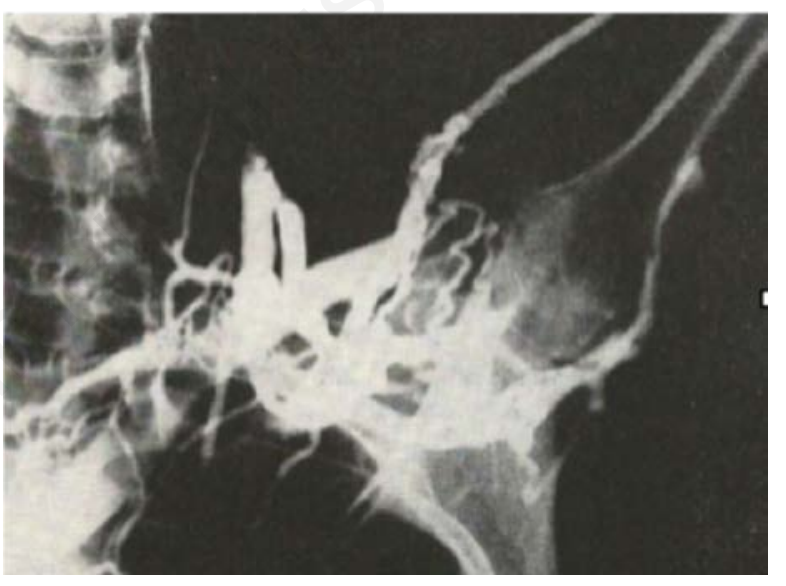

Figure 5. Dynamic phlebography performed in abduction of the limb shows in greater detail the obstruction of the succlavo-axillary venous axis and the dilation of the collateral venous pathways.

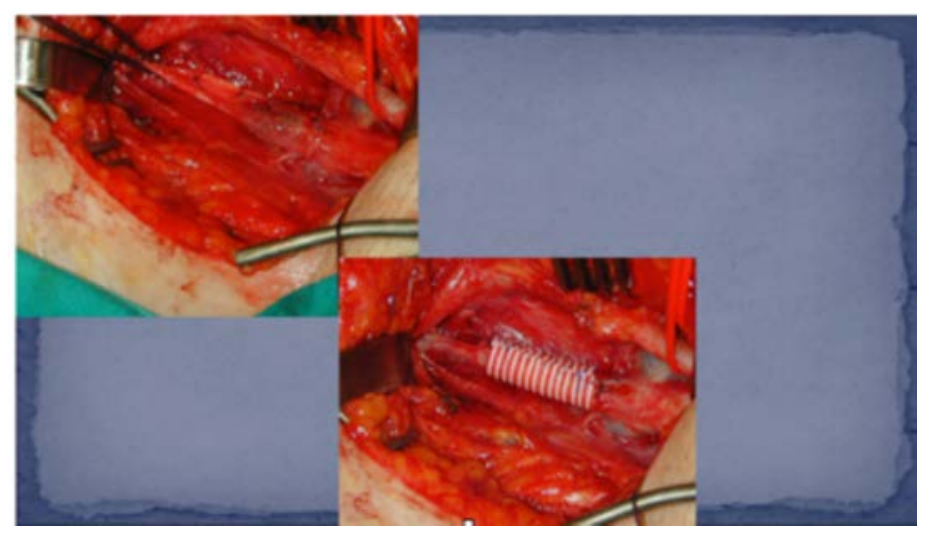

Figure 6. External valvuloplasty by transmural suture. Milking maneuver and subsequent bandage with prosthetic sleeve. 


\section{Venous ulcer}

This cultural path has naturally led me to focus cultural attention on the resulting extreme clinics of chronic venous disease, namely venous ulcer. In recent years, the scientific contributions of authoritative Italian and foreign Authors on the subject of venous pathophysiology, microcirculation, venous valvular reconstruction, restorative and regenerative surgery have enabled the therapeutic baggage to be considerably enriched. The hemodynamic study and holistic view of the patient suffering from such a severe and disabling condition remains essential. ${ }^{18-20}$

\section{Conclusions}

The cultural message of a Master lies in the attitude of man and the clinician in the face of the disease. Observation, study, comparison, prudence and finally the decision of intervention, even invasive and aggressive if conditions so require, to be completed with dexterity and resolution, are the way forward.

Venous pathology does not generally involve dramatic clinical pictures such as arterial disease, but is not less chronic, it can be fatal, as in venous thromboembolism, or severely disabling as in the case of post-thrombotic syndrome and venous ulcer. It is therefore precisely in this pathology that early and accurate diagnosis and prompt and personalized therapeutic intervention can give healing to patients.

In this field the work of Aureliano Puglionisi constitutes a heritage to be collected and kept alive.

\section{References}

1. Malan E, Puglionisi A. Congenital angiodysplasias of the extremities, I, Generalities and classification; venous dysplasias. J Card Surg 1964;5:87-30.

2. Malan E, Puglionisi A. Arterial, arterial and venous, and haemolymphatic dysplasias. J Card Surg 1965;6:255-345.

3. Puglionisi A, Di Giovanni V, Camilli S, Cina G. Problemi di Terapia Chirurgica delle Phlebotrombosi Acute degli Arti. In: Archivio ed Atti della Società Italiana di Chirurgia. $74^{\circ}$ Congresso Nazionale, 15-18 ottobre 1972; Roma. Padova: Piccin Editore; 1972. I:391-471.

4. Puglionisi A, Di Giovanni V. Trombosi venose acute degli arti inferiori. In: Trattato di tecnica chirurgica. Chirurgia Vascolare 1980;14:1092-111.

5. Meissner MH, Gloviczki P, Comerota AJ, et al. Early thrombus removal strategies for acute deep venous thrombosis: clinical practice guidelines of the Society for Vascular Surgery and the American Venous Forum. J Vasc Surg 2012;55:1449-62.

6. Eklof B. Surgical thrombectomy for iliofemoral venous thrombosis revisited. Vasc Surg 2011;54:897-900.

7. Camilli S, Guarnera G, Cina G, Snider F. Sostituzione della vena cava inferiore con protesi di Dacron a doppio velour. Studio sperimentale. Chirur Patol Sper 1979;27:290-304.

8. Puglionisi A, Picciocchi A, Cina G, et al. Implicazioni delle Vene Cave in Chirurgia Generale. In: Archivio ed Atti della Società Italiana di Chirurgia, $82^{\circ}$ Congresso Nazionale, 27-30 ottobre 1980; Roma. Milano: Edizioni Masson; 1980.

9. Puglionisi A, Di Giovanni V, Snider F, et al. Surgical tretment of thromboses of the inferior vena cava. J Chir (Paris) 1983;120:481-6.

10. Puglionisi A, Di Giovanni V, Camilli S, et al. Sindromi compressive neurovascolari dell'arto superiore a carattere prevalentemente venoso. Archiv Chir Torac Cardiovasc
1979;1:70-81.

11. Puglionisi A, Camilli S, Guarnera G. La sindrome neurovascolare dell'arto superiore. Risultati della terapia chirurgica. Minerva Cardioangiol 1983;31:727-31.

12. Camilli S, Guarnera G. Terapia medica e chirurgica delle ostruzioni venose dell'arto superiore. Minerva Angiol 1983;8:7-14.

13. Craig Miller D, Roon AJ. Diagnosi e trattamento delle malattie vascolari periferiche. Presentazione di A. Puglionisi - Traduzione di S. Camilli, G. Guarnera. Milano: Masson Ed.; 1985.

14. Camilli S, Guarnera G. L'insufficienza venosa profonda primaria e le possibilità della chirurgia ricostruttiva. Padova: Piccin Ed.; 1991.

15. Camilli S, Guarnera G. Surgical reconstruction in deep venous insufficiency. Phlebologie 1992;45:3319.

16. Camilli S, Guarnera G. External banding valvuloplasty of the superficial femoral vein in the treatment of primary deep valvular incompetence. Int Angiol 1994;13:218-22.

17. Guarnera G. Regarding does surgical correction of the superficial femoral vein valve change the course of varicose disease? J Vasc Surg 2001;34:374-5.

18. Guarnera G, Bonadeo P, Marchitelli E, Crespi A. La terapia farmacologica e chirurgica dell'ulcera venosa. Acta Vulnol 2010;8:205-50.

19. O'Donnell TF, Passman MA, Marston WA, et al. Management of venous leg ulcers. Clinical practise guidelines of the Sciety for Vascular Surgery and the American Venous Forum. J Vasc Surg 2014;60:3S-59S.

20. Guarnera G. Ulcere Vascolari degli arti inferiori. Torino: Edizioni Minerva Medica; 2016. 